\title{
Effective Removal of Hazardous Dyes from Aqueous Solutions Using Starch Based Hydrogel and Gamma Radiation
}

\author{
Ghada Adel Mahmoud", Samia E. Abdel-Aal, Nabil A. El-kelesh, E. A. Alshafei \\ Polymer Chemistry Department, National Center for Radiation Research and Technology (NCRRT), Egypt
}

Copyright $(2017$ by authors, all rights reserved. Authors agree that this article remains permanently open access under the terms of the Creative Commons Attribution License 4.0 International License

\begin{abstract}
The adsorption performance of acrylamide/ starch hydrogel (AAm/starch) prepared by gamma radiation for removal of direct congo red (DCR) and direct blue (DB) dyes has been investigated. The physico-chemical parameters such as dye concentration, solution $\mathrm{pH}$ and temperature have been studied. Favorable adsorption occurred at $\mathrm{pH} 3$ for DCR and $\mathrm{pH} 10$ for $\mathrm{DB}$. The adsorption of dyes onto AAm/starch hydrogels was endothermic process. Experimental data have been modeled by the Freundlich isotherm. Degradation test of DCR and DB dyes using gamma irradiation in aqueous solution under various radiation doses and $\mathrm{pH}$ was investigated and G-value was calculated. Destruction of $70 \%$ and $75 \%$ of the dye colour solutions was succeeded at radiation dose 40 and $30 \mathrm{kGy}$ for DCR and DB, respectively. Comparing the removal percent of $\mathrm{DCR}$ and $\mathrm{DB}$ dyes by radiation degradation with that done by AAm/starch hydrogel adsorption was investigated. It was found that preferring removal of DCR and DB dyes by gamma radiation degradation. The remaining concentration of dyes was followed by adsorption onto the hydrogel. Complete removal of DCR and DB was performed by gamma radiation degradation followed by $\mathrm{AAm} / \mathrm{starch}$ hydrogel adsorption.
\end{abstract}

Keywords Adsorption, Hydrogel, Gamma Radiation, Dye Degradation, G-Value

\section{Introduction}

The pollution from dye wastewater is one of the most important environmental problems due to the fact that the use of a variety of dyes has increased [1,2]. The colour seems to be the most undesired one, as human eyes can most easily recognize it [3]. Many treatment processes have been applied for the removal of dyes from wastewater such as physical, chemical and biological treatments. The physical and chemical treatment methods include ozonization, adsorption, chemical precipitation, flocculation and coagulation [4].

Adsorption is one of the most common methods used in wastewater treatment because it is economical, effective and simple in design. The adsorption process is influenced by the nature of the adsorbate and the substituent groups of adsorbents [5]. However, the adsorption method can only transfer the contaminants (dyes) from one phase to the other leaving the problem essentially unsolved. This problem can be solved by combining the conventional techniques with other techniques. Therefore, attention has to be focused on techniques that lead to the complete destruction of the dye molecules $[6,7]$.

Radiation is the unique source of energy that can initiate chemical reactions at any temperature, including ambient, under any pressure, in any phase (gas, liquid or solid), without the use of catalysts. Gamma rays are ionizing radiations that interact with the material by colliding with the electrons in the shells of atoms. The energy carried by the gamma radiation is transferred to the product being irradiated by collisions between the radiation and the atoms of the product. In these collisions, atoms lose their bound electrons in the ionization process [8].

Hydrogels are polymeric materials that imbibe a considerable amount of water within a polymeric network without dissolution in water while keeping its three-dimensional stability. These hydrogels are suitable for dyes removal due to their hydrophilic nature and three-dimensional polymeric network which can imbibe large amounts of water [9-11]. The radiation technique seems an excellent method for the preparation of hydrogels, in radiation processing technology initiator, catalyst, and cross-linker are not required because ionizing radiation is highly energetic [12]. This technique has many advantages such as easy process control and the technology is environment-friendly since it leaves no residue or pollutant in the environment $[2,3]$.

This study is divided into three parts, the first one was 
investigated the adsorption of (DCR) and (DB) dyes by (AAm/starch) hydrogel that prepared by gamma radiation. The second part was degradation of the two dyes by gamma radiation. Factors affected the adsorption and degradation of dyes was studied. The novelty of the present study lays on the third part, where, adsorption of remaining dyes after their degradation to complete removal of (DCR) and (DB) dyes.

\section{Materials and Methods}

\subsection{Materials}

Water soluble starch was received from Nasr Company for Medical Supplies, Egypt, and was used as received. Acrylamide (AAm) from Sigma and used as received. Dyes were purchased from Aldrich, Milwaukee, WI, USA, and used as received (Table 1). Other chemicals, such as citrate and phosphate buffer salts of analytical reagents were purchased from El-Nasr Co. for Chemical Industries, Egypt. Distilled water was used to prepare the solutions. All solutions were freshly made at room temperature shortly before using deionized distilled water.

\subsection{Preparation of AAm/Starch Hydrogels}

Starch powder $(1 \mathrm{~g})$ was dissolved in $(100 \mathrm{ml})$ distilled water, heated and stirred at $80^{\circ} \mathrm{C}$ for $30 \mathrm{~min}$ to form a homogeneous mixture. The starch was cooled to room temperature then AAm of $60 \%$ concentration was added and continuously stirred at room temperature for $30 \mathrm{~min}$. The viscous solution was transferred into the glass tube to be irradiated by ${ }^{60} \mathrm{Co}$ gamma source at radiation dose $20 \mathrm{kGy}$ and radiation dose rate $1.2 \mathrm{~Gy} / \mathrm{sec}$ at room temperature. After copolymerization, the vials were broken; the formed polymeric cylinders were removed and cut into discs of 2 $\mathrm{mm}$ thickness and $5 \mathrm{~mm}$ diameter. All samples were washed in excess water to remove the unreacted component, then air dried at room temperature.

\subsection{Gamma Radiation Treatment of Dyes}

The various concentrations of dyes were subjected to gamma radiation (gamma cell type $4000 \mathrm{~A}$, India), at room temperature in ambient humidity. The absorbed doses were; $5,10,15,20,30$ and $40 \mathrm{kGy}$ at radiation dose rate of 1.2 Gy/sec.

\subsection{Adsorption Studies}

Batch adsorption experiments were carried out at different temperatures between 20 and $60^{\circ} \mathrm{C}$. Exactly $50 \mathrm{ml}$ of dye solution of known initial concentration $(50-500 \mathrm{mg} / \mathrm{L})$ was shaken at the certain agitation speed $(250 \mathrm{rpm})$ with a known dose of AAm/starch hydrogel for $1440 \mathrm{~min}$. The $\mathrm{pH}$ of the solution was adjusted to the required value by acetate and phosphate buffers. The dye concentration was determined at the maximum absorbance wavelength of dyes $\left(\lambda_{\max }\right)$ using UNICAM UV-Vis Spectrometer, Model 1000.

The dye uptake quantity (mg dye/g adsorbent) was determined as follows:

$$
q e=\frac{(\mathrm{C} \circ-\mathrm{Ce})}{\mathrm{m}} \times V
$$

where $\mathrm{q}_{\mathrm{e}}$ is the equilibrium adsorption capacity of dye adsorbed on unit mass of adsorbent $(\mathrm{mg} / \mathrm{g}), \mathrm{C}_{0}$ and $\mathrm{C}_{\mathrm{e}}$ are the initial and the equilibrium concentrations $(\mathrm{mg} / \mathrm{L})$, respectively, $\mathrm{V}$ is the volume of adsorbate solution (L) and $\mathrm{m}$ is the mass of adsorbent $(\mathrm{g})$.

The percentage of dye removal was calculated using the following relationship:

$$
\operatorname{Re} \operatorname{moval}(\%)=\frac{\left(\mathrm{C}_{0}-\mathrm{C}_{\mathrm{t}}\right)}{\mathrm{C}_{0}} \times 100
$$

where $\mathrm{C}_{0}$ and $\mathrm{C}_{\mathrm{t}}$ (both in $\mathrm{mg} / \mathrm{L}$ ) are the initial dye concentration and the dye concentration at any time $(\mathrm{t})$, respectively.

\section{Results and Discussion}

\subsection{Adsorption of Dyes by AAm/Starch Hydrogels}

The adsorption process is influenced by the nature of the adsorbate and its substituent groups. The ionic functional groups in the hydrogels can absorb and trap ionic dyes from wastewaters. Batch methods are widely used to describe the adsorption capacity and the adsorption kinetics. In batch systems, the parameters of the adsorbate such as $\mathrm{pH}$, concentration and temperature can be controlled and/or adjusted. In this part factors affecting adsorption of DCR and DB dyes by AAm/starch hydrogel such as initial dye concentration, $\mathrm{pH}$ and temperature are evaluated.

\subsubsection{Influence of Initial PH}

The $\mathrm{pH}$ of the solution affects the extent of adsorption because the distribution of surface charge of the adsorbent can be changed with $\mathrm{pH}$ [13]. The effect of initial $\mathrm{pH}$ of the medium on the adsorption of DCR and DB dyes onto was examined over $\mathrm{pH}$ range values between 3 to 10 onto AAm/starch hydrogel and the results are presented in Figure 1. The results show that the dye removal percent of DCR decreased with increasing the initial $\mathrm{pH}$ of the dye from 3 to 10 and maximum removal occurred at $\mathrm{pH}=3$ [14]. $\mathrm{At} \mathrm{pH}=3$, highly electrostatic attraction exists between the positively charged surfaces of the hydrogel and negatively charged of DCR anionic dye. DCR molecule with two sulfonic groups ionized easily even in acidic media and became a soluble DCR anion which was easily adsorbed onto AAm/starch hydrogel with positive surface charge [15]. As the $\mathrm{pH}$ of the system increases, the numbers of negatively charged sites on the adsorbent also increased which does not favor the adsorption of DCR dye due to the electrostatic repulsion. In 
alkaline medium the presence of excess $\mathrm{OH}^{-}$ions destabilizing anionic dyes and competing with the dye anions for the adsorption sites which lead to a decrease in removal percent. This behavior is reversed for adsorption of DB onto AAm/starch hydrogel. As shown in Fig. 1, as the $\mathrm{pH}$ of the $\mathrm{DB}$ dye solution increased from 3 to 10 proportional increases in adsorption takes place and the maximum adsorption of $\mathrm{DB}$ onto $\mathrm{AAm} / \mathrm{starch}$ hydrogel occurred at $\mathrm{pH}=10$. The interaction of the $\mathrm{DB}$ dye molecules and the adsorbed species may follow extremely complicated patterns. As $\mathrm{pH}$ of the dye solution increases a successive deprotonation of positively charged groups on the AAm/starch hydrogel and thus, electrostatic repulsion within the hydrogel makes the hydrogel dramatically swelled, the $\mathrm{Na}+$ ions in the buffering media shield the carboxylate anions and increase the electrostatic attraction between adsorbed species and dye anions.

\subsubsection{Influence of Initial Dye Concentration}

Initial dye concentration is one of the important factors that affect the adsorption kinetics. It means that the adsorption is highly dependent on the initial concentration of dye. The adsorption process is proportional to the initial dye concentration because it drives the mass transfer rate under a higher concentration gradient between dye solution and hydrogel surface [16]. Figure (2) illustrates the influence of the initial dye concentration on the dye removal percent onto AAm/starch hydrogel by varying dye concentration from 50 up to $500 \mathrm{mg} / \mathrm{L}$. The results show that, the dye removal percent of DCR decreased with increasing the initial dye concentration from 50 to $100 \mathrm{mg} / \mathrm{L}$ after that a little increase in the removal percent was observed. For DB dye the removal percent decreased with increasing dye concentration. At low concentration, the ratio of the initial number of dye molecules to the available surface area is low subsequently; the fractional adsorption becomes independent of the initial dye concentration. But, at higher concentration the available sites of adsorption becomes fewer and hence the percentage removal of dye is dependent upon the initial dye concentration [17]. A decreasing in the dye concentration in the solution, molecules of the adsorbate have more chance to react with the available active sites on the adsorbent and, as a result, the adsorption rate was increased as in the case of DB adsorption. Hence, one can claim that one method to increase the percentage of dye removal is dilution of wastewater [18]. At high dye concentration, accumulation of dye ions on the surface is occurred. Such accumulation decreases the availability of the total surface area of the sorbent particles for adsorption.

\subsubsection{Adsorption Isotherm}

The equilibrium isotherm in this study has been described in terms of the Freundlich isotherm. It is most often used to describe the adsorption of organic components in a solution $[19,20]$. This model applies to the adsorption on heterogeneous surfaces with the interaction between the adsorbed molecules and is not restricted to the formation of a monolayer. This model assumes that as the adsorbate concentration increases, the concentration of adsorbate on the adsorbent surface also increases and, correspondingly, the sorption energy exponentially decreases on completion of the sorption centers of the adsorbent. The well-known expression for the Freundlich model is given as [21]:

$$
\log \mathrm{qe}=\log \mathrm{Kf}+1 / \mathrm{n} \log \mathrm{Ce}
$$

where $\mathrm{q}_{\mathrm{e}}$ is the amount adsorbed at equilibrium $(\mathrm{mg} / \mathrm{g}), \mathrm{K}_{\mathrm{f}}$ is the Freundlich constant, $1 / \mathrm{n}$ is the heterogeneity factor which is related to the capacity and intensity of the adsorption, $\mathrm{n}$ is an empirical parameter that varies with the degree of heterogeneity and is related to the distribution of bonded ions on the sorbent surface and $\mathrm{C}_{\mathrm{e}}$ is the equilibrium concentration $(\mathrm{mg} / \mathrm{L})$. The values of $\mathrm{n}$ and $\mathrm{K}_{\mathrm{f}}$ can be obtained from the slope and intercept of the plot of $\log \mathrm{q}_{\mathrm{e}}$ against $\log$ $\mathrm{C}_{\mathrm{e}}$ and the results are given in Table 2. High $\mathrm{R}^{2}$ values of the straight lines obtained at each temperature confirmed the validity of the Freundlich adsorption isotherm for adsorption. The value of the Freundlich constant $\left(\mathrm{K}_{\mathrm{f}}\right)$ represents the degree of adsorption. The values of $\mathrm{n}$ are higher than one at all temperatures indicated the favorable adsorption. This value increased with increasing temperature for both dyes indicated more favorable adsorption at high temperature.

\subsubsection{Influence of Temperature}

Effect of temperature on the removal of DCR and DB dyes onto AAm/starch hydrogel was performed at three different temperatures: 20,40 , and $60^{\circ} \mathrm{C}$ and the results are shown in Fig.3. The results indicated that by increasing the temperature from 20 to $60^{\circ} \mathrm{C}$, the adsorption capacity of DCR and DB onto the hydrogel also increased. This indicated that the sorption of dyes onto AAm/starch hydrogels is an endothermic process. The temperature affects the adsorption rate by altering the molecular interactions and the solubility [22]. Increasing the dye removal with increasing temperature may be attributed to a chemical reaction taking place between the functional groups of the adsorbate/adsorbent and the dye [23] which considered endothermic reaction. This may be caused by the increased tendency of adsorbate ions mobility with temperature which slightly enhanced the adsorption of dyes from the solution into the hydrogel [24].

Spontaneity of a process can be determined by thermodynamic parameters such as enthalpy change $\left(\Delta \mathrm{H}^{\circ}\right)$, free energy change $\left(\Delta \mathrm{G}^{\circ}\right)$ and entropy change $\left(\Delta \mathrm{S}^{\circ}\right)$. A spontaneous process will show a decrease in $\Delta \mathrm{G}^{\circ}$ and $\Delta \mathrm{H}^{\circ}$ values with increasing temperature. The temperatures used in the thermodynamic study were 293,313 and $333 \mathrm{~K}$. The thermodynamic parameters were calculated based on the following equations:

$$
\begin{aligned}
& \Delta \mathrm{G}^{\mathrm{o}}=\Delta \mathrm{H}^{\mathrm{o}}-\mathrm{T} \Delta \mathrm{S}^{\mathrm{o}} \\
& \ln k=\frac{\Delta S^{o}}{R}-\frac{\Delta H^{o}}{R T}
\end{aligned}
$$

where $k$ is the equilibrium constant, $R$ is the universal gas constant $(8.314 \mathrm{~J} / \mathrm{mol} \mathrm{K})$ and $T$ is the temperature $(K)$. The 
values of $\Delta H^{\circ}$ and $\Delta S^{\circ}$ were calculated from the slope and intercept of the plot between ' $I n k$ ' versus $1 / T$, respectively, and the data is summarized in Table (3).

The positive values of $\Delta \mathrm{H}^{\circ}$ were obtained indicating the irreversible adsorption probably due to polar interaction [25, 26]. The decrease in $\Delta G^{o}$ values with increasing temperature indicated the feasibility of adsorption at higher temperature. These results indicated that at low temperature, the less driving force and hence resulting in less adsorption capacity but high temperature makes the adsorption easier and therefore, the adsorption is more favorable at high temperatures. Physisorption and chemisorption can be classified, to a certain extent, by the magnitude of the free energy change. It is accepted that the bonding strengths of $<84 \mathrm{~kJ} / \mathrm{mol}$ are typically those of physical adsorption type bonds. Chemisorption bond strengths can range from 84 to $420 \mathrm{~kJ} / \mathrm{mol}$ [27]. It can be also noted that the values of $\Delta \mathrm{S}^{\circ}$ are positive values indicated increasing the disorder at the solid/liquid interface during the adsorption of DCR and DB dyes onto the AAm/starch hydrogel.

\subsection{Degradation of Dyes Using Gamma Radiation}

Radiation-induced degradation of dyes is widely studied because it is relatively easy to measure color change during the course of an experiment. The disappearance of colour intensity is attributed to radiation-induced degradation of the characteristic chromophoric group followed by fragmentation of the complex molecule into simpler compounds. The decolouration of dye solution depends on the structural changes in the chromophoric groups of dyes. The influence of radiation dose on the degradation of DCR and DB dyes at the initial concentration of $500 \mathrm{mg} / \mathrm{L}$ at various pH's was investigated and observed in Figs (4 and 5), respectively. As observed in Figures, the dye concentration continuously decreased with the increase in radiation doses and the exposed dye solution was found to be discolored at high radiation dose $40 \mathrm{kGy}$ for DCR and $30 \mathrm{kGy}$ for DB which is an evidence of its structural changes. When the samples were gamma irradiated, radiolytic degradation was observed in dyes. During gamma radiolysis of dyes in aqueous solutions, it has been demonstrated that dyes can be decolored and degraded by gamma radiolysis [28]. The extent of dye destruction depends mainly on its concentration and radiation dose. The effect of gamma ray interaction with dye is to reduce absorption coefficient of the dye solutions as this interaction always increases the amount of $\mathrm{H}+$ ions in the aqueous solution of the dye, which will consequently increase the acidity of the samples [29]. This implies that gamma-ray induced degradation is more appropriate to be used as a pre-treatment method for reducing the dye toxicity.

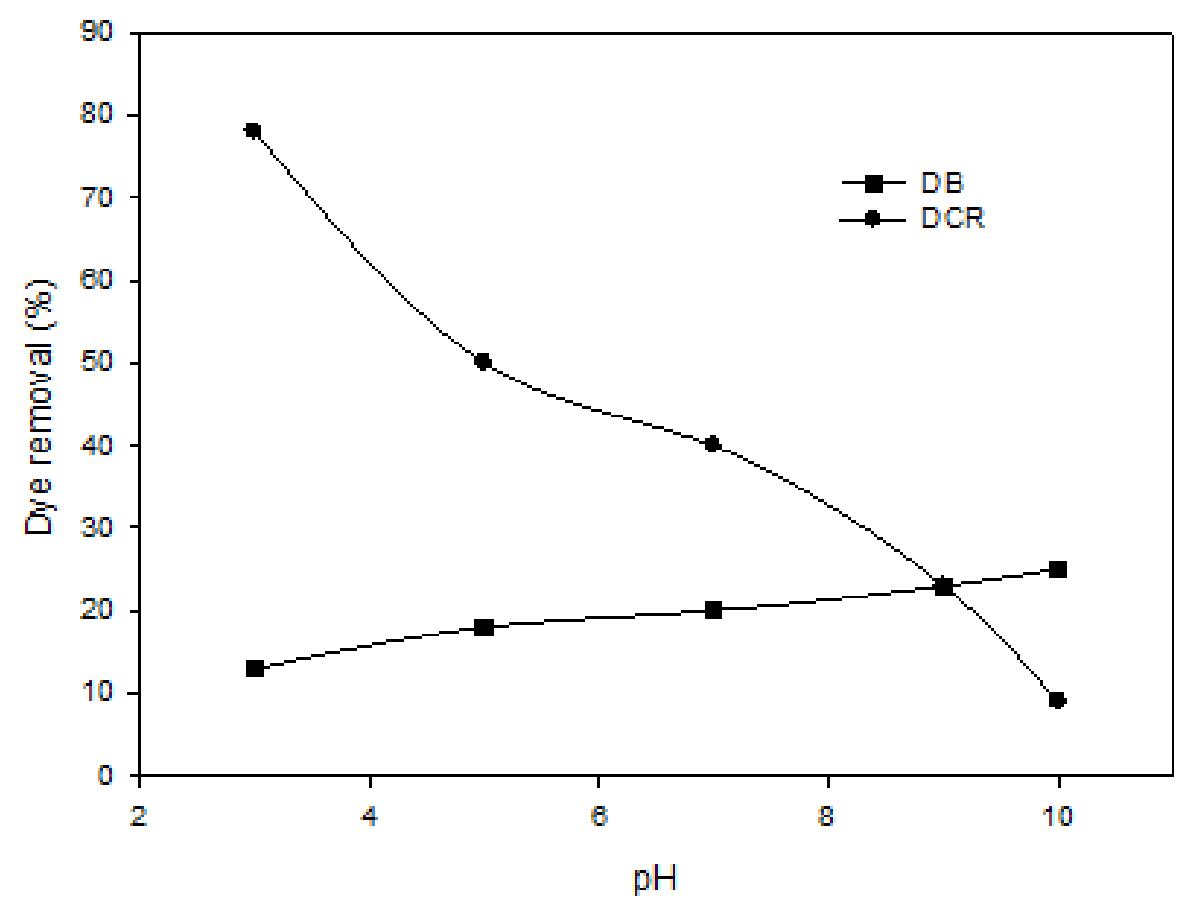

Figure 1. Effect of $\mathrm{pH}$ of medium on the removal percent of DCR and DB dyes onto AAm/starch hydrogels at room temperature and initial concentration $500(\mathrm{mg} / \mathrm{L})$ 


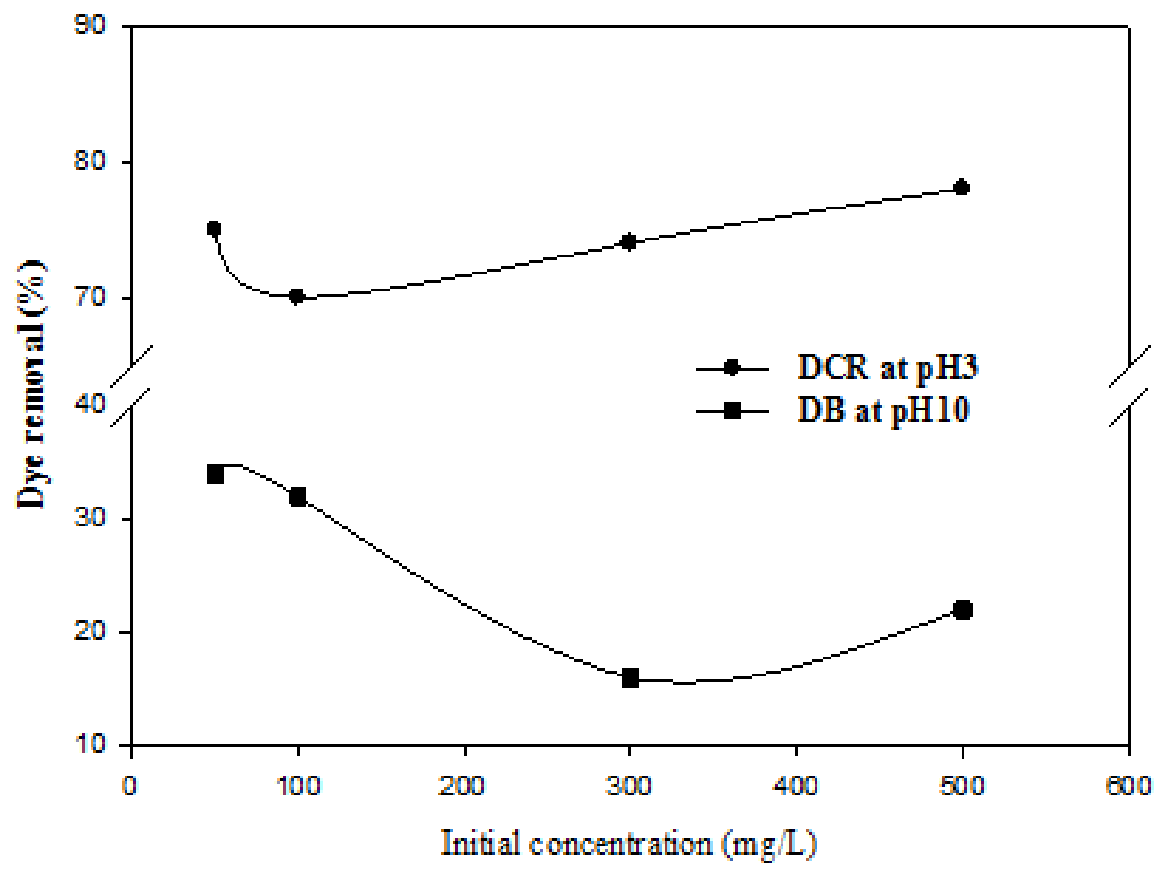

Figure 2. effect of initial dye concentration on the removal percent of DCR and DB dyes onto AAm/starch hydrogel at room temperature

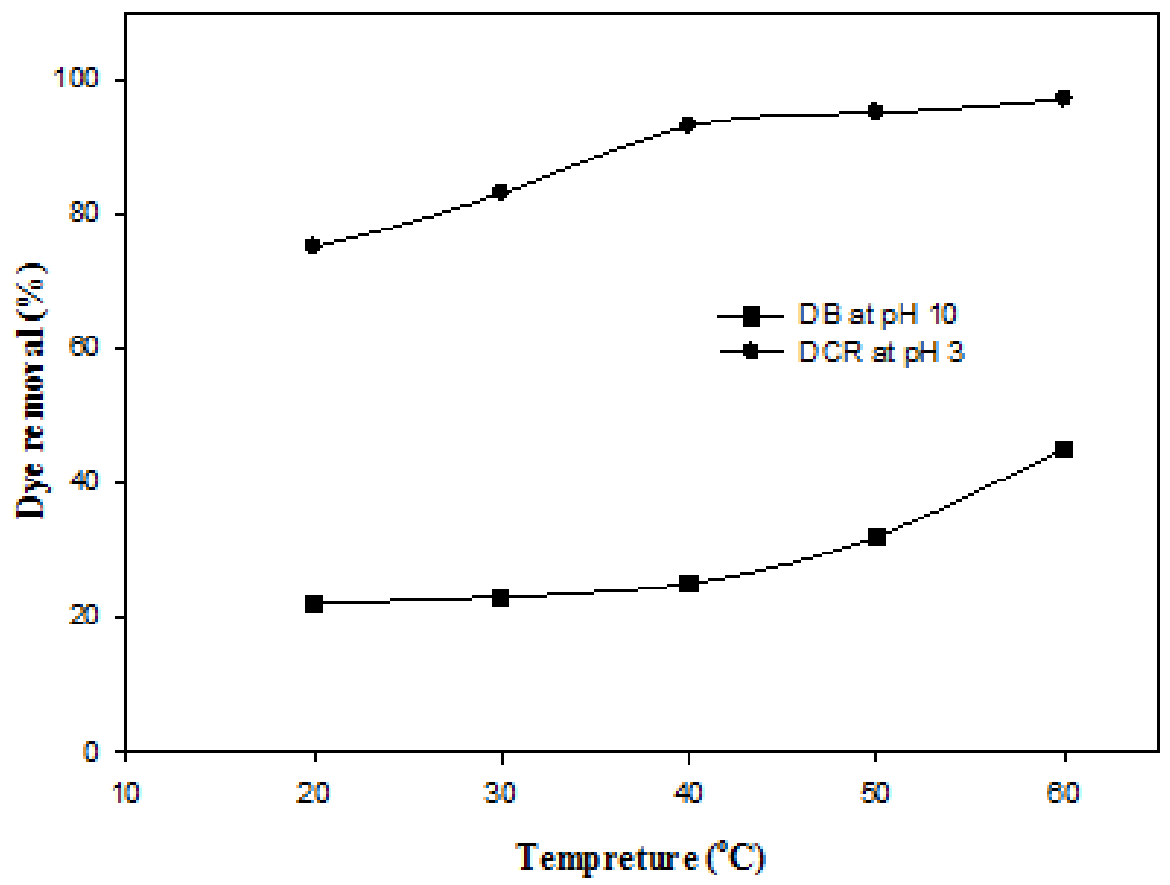

Figure 3. Effect of temperature on the removal percent of DCR and DB dyes onto AAm/starch hydrogel at initial dye concentration $500 \mathrm{mg} / \mathrm{L}$ 


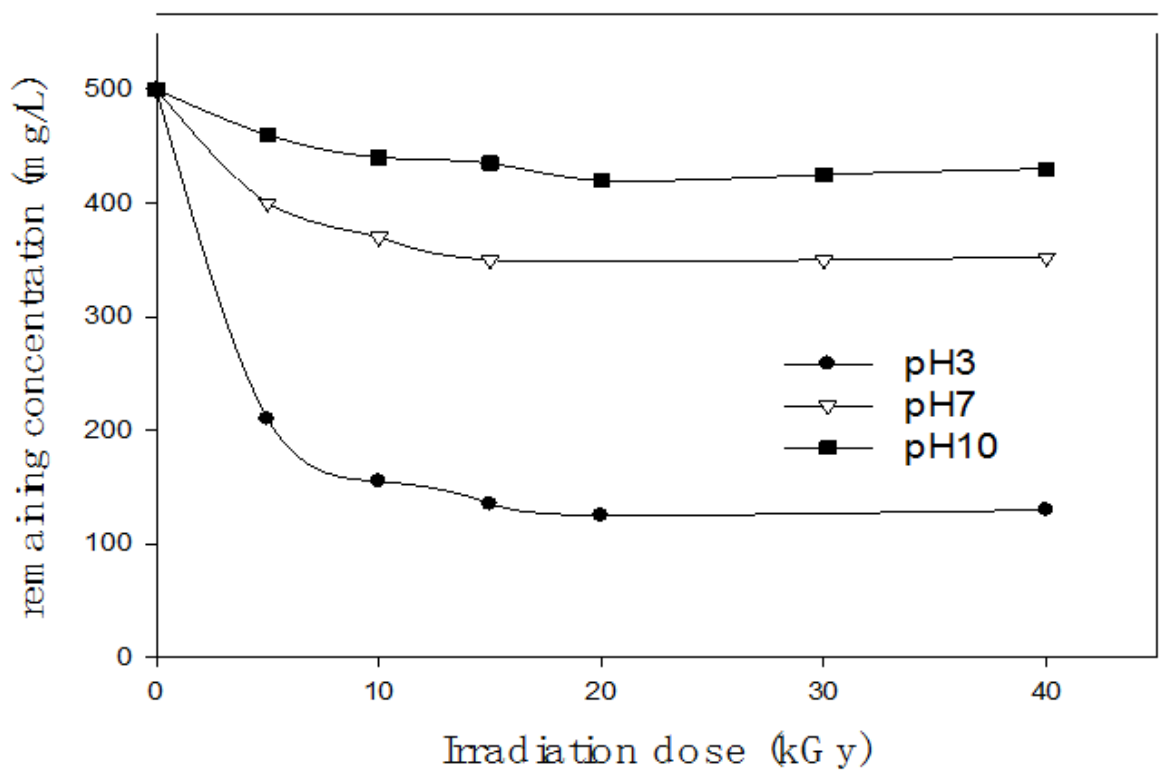

Figure 4. Effect of gamma radiation dose on degradation of DCR dye at initial concentration $500 \mathrm{mg} / \mathrm{L}$ and radiation dose rate $1.2 \mathrm{~Gy} / \mathrm{sec}$

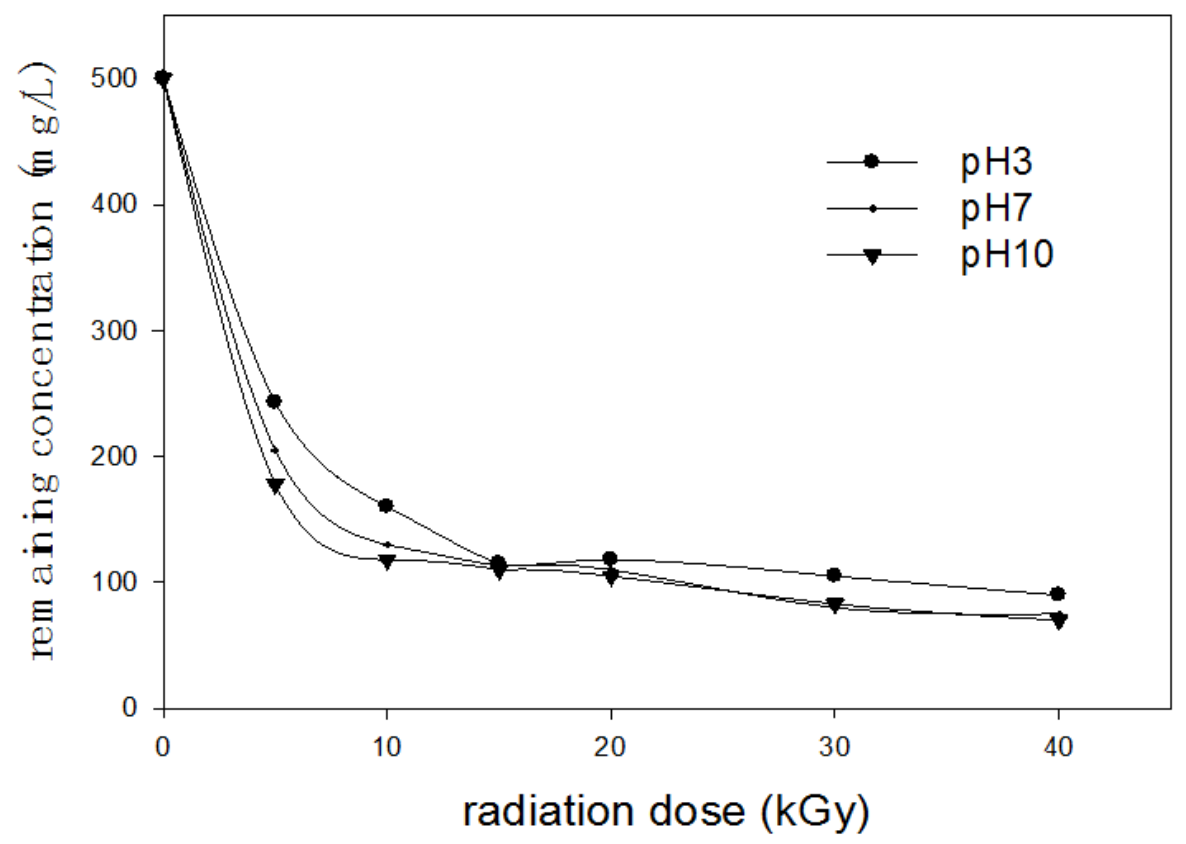

Figure 5. Effect of gamma radiation dose on degradation of DB dye at initial concentration $500 \mathrm{mg} / \mathrm{L}$ and radiation dose rate $1.2 \mathrm{~Gy} / \mathrm{sec}$ 
Table 1. Properties of dyes

\begin{tabular}{|c|c|c|}
\hline Properties & Direct Congo Red & Direct Blue \\
\hline $\begin{array}{l}\text { Common } \\
\text { name }\end{array}$ & C.I Direct red 28 & C.I Direct blue 14 \\
\hline $\begin{array}{l}\text { Chemical } \\
\text { structure }\end{array}$ & & $₹ \circ$ \\
\hline M.wt & 696.67 & 960 \\
\hline Dye type & Direct & Direct \\
\hline$\lambda_{\max }(\mathrm{nm})$ & 554 & 643 \\
\hline
\end{tabular}

Table 2. Isotherm constants of the Freundlich model for the adsorption of direct DCR and DB dyes onto AAm/starch hydrogel at various temperatures

\begin{tabular}{|c|c|c|c|c|c|c|}
\hline \multirow{2}{*}{ Isotherm parameters } & \multicolumn{3}{|c|}{ DCR } & \multicolumn{3}{c|}{ DB } \\
\cline { 2 - 7 } & $293 \mathrm{k}$ & $313 \mathrm{k}$ & $333 \mathrm{k}$ & $293 \mathrm{k}$ & $313 \mathrm{k}$ & $333 \mathrm{k}$ \\
\hline $\mathrm{n}$ & 1.04 & 1.2 & 1.35 & 1.5 & 1.7 & 4.8 \\
\hline $\mathrm{K}_{\mathrm{f}}\left(\mathrm{mg}^{1-1 / \mathrm{n}} \mathrm{L}^{1 / \mathrm{n}} \mathrm{g}^{-1}\right)$ & 1.2 & 3.6 & 10 & 0.2 & 2.82 & 1.7 \\
\hline $\mathrm{R}^{2}$ & 0.92 & 0.98 & 0.97 & 0.96 & 0.98 & 0.98 \\
\hline
\end{tabular}

Table 3. Thermodynamic parameters for adsorption of DCR and DB into AAm/starch hydrogel

\begin{tabular}{|c|c|c|c|c|c|}
\hline \multirow{2}{*}{$\begin{array}{l}\text { Initial concentration } \\
\mathrm{mg} / \mathrm{L}\end{array}$} & $\begin{array}{c}\Delta \mathrm{H} \\
\mathrm{kJ} / \mathrm{mol}\end{array}$ & $\begin{array}{c}\Delta \mathrm{S} \\
\mathrm{J} / \mathrm{mol}\end{array}$ & $\begin{array}{c}\Delta \mathrm{G}_{293} \\
\mathrm{~kJ} / \mathrm{mol}\end{array}$ & $\begin{array}{c}\Delta \mathrm{G}_{313} \\
\mathrm{~kJ} / \mathrm{mol}\end{array}$ & $\begin{array}{c}\Delta \mathrm{G}_{333} \\
\mathrm{~kJ} / \mathrm{mol}\end{array}$ \\
\hline & \multicolumn{5}{|c|}{ DCR dye } \\
\hline 50 & 15.6 & 64 & -3.18 & -4.46 & -5.74 \\
\hline 100 & 25.5 & 94 & -2.04 & -3.92 & -5.8 \\
\hline \multirow[t]{2}{*}{500} & 39.7 & 163 & -3.52 & -6.78 & -10.04 \\
\hline & \multicolumn{5}{|c|}{ DB dye } \\
\hline 50 & 35.7 & 86 & 0.54 & -1.86 & -4.26 \\
\hline 100 & 27.9 & 42 & 1.53 & -0.27 & -2.07 \\
\hline 500 & 17.7 & 83.2 & 3.05 & 2.05 & 1.05 \\
\hline
\end{tabular}


Table 4. G values of DCR and DB dyes degradation by gamma radiation at various $\mathrm{pHs}$ and concentrations.

\begin{tabular}{|c|c|c|c|c|c|}
\hline \multirow{3}{*}{$\mathrm{pH}$} & \multicolumn{5}{|c|}{ G values of dyes } \\
\hline & \multicolumn{5}{|c|}{ Initial concentration $(\mathrm{mg} / \mathrm{L})$} \\
\hline & 500 & 250 & 100 & 50 & 25 \\
\hline \multicolumn{6}{|c|}{ DCR dye } \\
\hline 3 & 0.26 & 0.140 & 0.014 & 0.012 & 0.011 \\
\hline 7 & 0.140 & 0.056 & 0.034 & 0.020 & 0.014 \\
\hline 10 & 0.035 & 0.042 & 0.031 & 0.020 & 0.014 \\
\hline \multicolumn{6}{|c|}{ DB dye } \\
\hline 3 & 0.260 & 0.160 & 0.094 & 0.032 & 0.040 \\
\hline 7 & 0.150 & 0.120 & 0.098 & 0.030 & 0.022 \\
\hline 10 & 0.110 & 0.100 & 0.092 & 0.030 & 0.010 \\
\hline
\end{tabular}

Radiation chemical yield, $(G$ value), is defined as the number of a particular species produced or destroyed per $100 \mathrm{eV}$ of energy absorbed by the system from ionizing radiation [30]. The G-value depends on the absorption bands of the dye, the concentration, and the radiation dose. G-values are calculated for various concentrations of DCR and DB dyes and given in Table (4). The $G$ values are decreased with the decreases in the dye concentration at various $\mathrm{pHs}$. This may be interpreted in terms of reactions of the intermediates of the water radiolysis with the dye molecules.

Comparing the removal percent of DCR and DB dyes by radiation degradation with that done by AAm/starch hydrogel adsorption was investigated. It can be observed that the removal percent of $500 \mathrm{mg} / \mathrm{L}$ of $\mathrm{DCR}$ by radiation degradation was $70 \%$ and by adsorption was $78 \%$. The removal percent of $500 \mathrm{mg} / \mathrm{L}$ of DB by radiation degradation was $75 \%$ and by adsorption was $28 \%$. This means that preferring removal of $\mathrm{DB}$ dyes by gamma radiation degradation.

\subsection{Adsorption of Remaining Dyes by Aam/Starch after Degradation Using Gamma Radiation}

The exposure of 500 of $\mathrm{mg} / \mathrm{L}$ of DCR and DB dyes to gamma radiation is resulted in decreasing concentration of dyes with the increase in radiation dose until reached to steady state. The remaining concentration of dyes is followed by adsorption with AAm/starch hydrogel. Complete removal of DCR and DB was obtained by gamma radiation degradation followed by $\mathrm{AAm} / \mathrm{starch}$ hydrogel adsorption. This may be due to that the degradation of DCR and DB dyes by gamma radiation is resulted in small fragment which was highly adsorbed on the surface of AAm/starch hydrogel. When gamma radiation interacts with the complex dye molecules, degradation occur and the possible products may be low molecular mass carboxylic acids which highly adsorbed on the hydrogel surface [31]. It can be concluded that this method is very effective for removal of high concentration dyes from the solution. It is well known that most colored material undergo bleaching or decolorization when exposed to high energy ionizing radiations, which is why gamma radiation source can be considered as alternative method for removing of high dye concentrations.

\section{Conclusions}

AAm/starch hydrogel prepared by gamma radiation was used for removal of DCR and DB dyes from aqueous solution. Favorable adsorption occurs at $\mathrm{pH} 3$ for DCR and $\mathrm{pH} 10$ for DB. The adsorption of dyes onto AAm/starch hydrogels is an endothermic process. Freundlich isotherm was made at different temperatures and their constants were calculated. Thermodynamic parameters such as $\left(\Delta \mathrm{H}^{\circ}\right),\left(\Delta \mathrm{G}^{\circ}\right)$ and $\left(\Delta \mathrm{S}^{\circ}\right)$ were calculated. The negative values of $\Delta \mathrm{G}^{\circ}$ indicate the spontaneity of the process, whereas the positive values of $\Delta \mathrm{H}^{\circ}$ and $\Delta \mathrm{S}^{\circ}$ indicate the endothermic nature and increase in randomness of the process, respectively. The degradability of DCR and DB dyes at initial concentration of $500 \mathrm{mg} / \mathrm{L}$ at various $\mathrm{pH}$ 's was examined and G- values were calculated. Comparing the removal percent of $\mathrm{DCR}$ and $\mathrm{DB}$ dyes by radiation degradation with that done by AAm/starch hydrogel adsorption is investigated. It can be observed that the removal percent of DCR and DB by radiation degradation was 70 and $75 \%$ by adsorption was 78 and $28 \%$, respectively. This means that preferring removal of DB dyes by gamma radiation degradation. Complete removal of DCR and DB was obtained by gamma radiation degradation followed by AAm/starch hydrogel adsorption.

\section{REFERENCES}

[1] S.T. Akar, R. Uysal. Untreated clay with high adsorption capacity for effective removal of C.I. Acid Red 88 from aqeous solutions: Batch and dynamic flow mode studies, Chemical Engineering Journal, 162, 591-598 (2010).

[2] K. Balasubramani, N. Sivarajasekar. Adsorption studies of 
organic pollutants onto activated carbon, international journal of innovative research in Science, Engineering and Technology. 3(3), 10575-10581 (2014).

[3] R- K. Kannan, K. Senthilkumar, P. Akilamudhan, V. Sangeetha, B. Manikandan. Studies on effectiveness of low cost adsorbents in continuous column for textile effluents. International Journal of Bioscience, Biochemistry and Bioinformatics. 2(6), 398-402 (2012).

[4] G. Tchobanoglous, F.L. Burton, H.D. Stensel. Wastewater engineering treatment and reuse. McGraw-Hill Inc., New York, 1991

[5] H Kozuka, T Takagishi, K Yoshikawa, N. Kuroki, M. Mitsuishi. Binding of anthraquinone dyes by crosslinked polyvinylpyrrolidone. Journal of Polymer Science Part A Polymer Chemistry, 24(10), 2695-2700(1986)

[6] D. Georgiou, P. Melidis, A. Aivasidis, K. Gimouhopoulos. Degradation of azo-reactive dyes by ultraviolet radiation in the presence of hydrogen peroxide, Dyes and Pigments 52 , 69-78 (2002).

[7] L.A. Estroff, A. D. Hamilton. Water Gelation by Small Organic Molecules, Chemical Review 104, 1201-1218 (2004).

[8] Kátia Aparecida da Silva Aquino (2012). Sterilization by Gamma Irradiation, Gamma Radiation, Prof. Feriz Adrovic (Ed.), InTech, DOI: 10.5772/34901. Available from: http://www.intechopen.com/books/gamma-radiation/steriliza tion-by-gamma-irradiation

[9] G. A. Mahmoud, S. F. Mohamed, H.M. Hassan. Removal of methylene blue dye using biodegradable hydrogel and reusing in a secondary adsorption process, Desalination and water treatment, 54(10), 2765-2776 (2015).

[10] G.A. Mahmoud, S.E. Abdel-Aal, N.A. Badway, S.A. Abo Farha, E.A. Alshafei. Radiation synthesis and characterization of starch-based hydrogels for removal of acid dye, Starch/Stärke, 65, 1-10 (2013).

[11] G.A. Mahmoud, S.E. Abdel-Aal, N.A. Badway, A.A. Elbayaa, D. F. Ahmed. A novel hydrogel based on agricultural waste for removal of hazardous dyes from aqueous solution and reuse process in a secondary adsorption, Polymer Bulletin, DOI 10.1007/s00289-016-171 7-0 (2016).

[12] S.T. Akar, R. Uysal. Untreated clay with high adsorption capacity for effective removal of C.I. Acid Red 88 from aqeous solutions: Batch and dynamic flow mode studies. Chemical Engineering Journal, 162, 591-598 (2010).

[13] E.K. Putra, R. Pranowo, J. Sunarso, N. Indraswati, S. Ismadji. Performance of activated carbon and bentonite for adsorption of amoxicillin from wastewater: Mechanisms, isotherms and kinetics, Water Research, 43, 2419-2430 (2009).

[14] M. A Zulfikar, H. Setiyanto. Adsorption of Congo Red From Aqueous Solution Using Powdered Eggshell, International Journal of Chem Tech Research, 5(4), 1532-1540 (2013).

[15] V. Jaikumara, K.S. Kumar, D.G. Prakash. Biosorption of acid dyes using spent brewery grains: Characterization and modeling, International Journal of Applied Science and Engineering, 7(2), 115-125 (2009).
[16] N. Mohammed, N. Grishkewich, R. M. Berry, K.C. Tam. Cellulose nanocrystal-alginate hydrogel beads as novel adsorbents for organic dyes in aqueous solutions, Cellulose, 22(6) 3725-3738 (2015).

[17] S. K. Ponnusamy, R. Subramaniam. Process optimization studies of Congo red dye adsorption onto cashew nut shell using response surface methodology, International Journal of Industrial Chemistry, 4(1), 1-10 (2013).

[18] G.B. Rao, G. Kalyani, B.V. Saradhi, Y.P. Kumar. Removal of fluoride from aqueous solution using a waste material. Nature Environment and Pollution Technology, 8(2), 231-236(2009).

[19] S. Arivoli, M. Hema. Comparative study on the adsorption kinetics and thermodynamics of dyes onto acid activated low cost carbon International Journal of Physical Sciences, 2(1) 10-17 (2007).

[20] C. Namasivayam, R.T. Yamuna, J. Jayanthi. Removal of methylene blue from wastewater by adsorption on cellulosic waste, orange peel, Cellulose Chemistry and Technology, 39, 333-339 (2003).

[21] J. Eastoe, J. S. Dalton. Dynamic surface tension and adsorption mechanisms of surfactants at the air-water interface, Advances in Colloid and Interface Science, 85, 103-144(2000).

[22] K.K. Panday, G. Prasad, V.N. Singh. Copper removal from aqueous solution by fly ash, Water, Air, \& Soil Pollution, 27, 287-292 (1968).

[23] B.H. Hameed, A.A. Ahmad, N. Aziz. Isotherms, kinetics and thermodynamics of acid dye adsorption on activated palm ash. Chemical Engineering Journal, 133, 195-203 (2007).

[24] M. Alkan, M. Dogan. Adsorption kinetics of victoria blue onto perlite Fresenius Environmental Bulletin, 12, 418-425(2003).

[25] W. A. Powell, C. M. Catranis, C. A. Maynard. Design of self-processing antimicrobial peptides for plant protection, Letters in Applied Microbiology, 31, 163- 168 (2000).

[26] H. Khanmohammadi, M. Erfantalab, New 1, 2, 4-triazole-based azo- azomethine dyes. Part I: Synthesis, characterization and spectroscopic studies. Spectrochimica Acta Part A: Molecular and Biomolecular Spectroscopy, 86, 39-43(2012).

[27] S.A.Dogbe, G. Emi-Reynolds, G. K. Banini, Gamma radiation treatment of waste waters from textile industries in Ghana, Journal of Applied Science and Technology, 6, 13 (2001).

[28] A. S. Al-Gorair, L. A. Al- Mutabagani, A. A. Al-Suhybani, Journal of Saudi Chemical Society. 11, 163 (2007).

[29] K.K. Panday, C.I. Prasad, V.N. Singh. Use of wollastonite for the treatment of $\mathrm{Cu}$ (II) rich effluents, Water Research, 19, 869-872 (1989).

[30] G.L. Clark. Encyclopedia of X-rays and Gamma Rays, Chapman \& Hall Ltd., London, UK (1963).

[31] G. V. Buxton, C.L. Greenstock, W.P. Helman, A.B. Ross, Journal of Physics and Chemistry, 17, 513 (1988). 